\title{
The Feasibility and Effectiveness of using Bragg Breakwaters in the Shore- line Wave Climate for East Taiwan Ocean Energy
}

\author{
Chih-Chung Wen ${ }^{1}$, Tsung-Lin Lee ${ }^{2,}$, Chien-Lin Chen ${ }^{3}$, Yong-Jun Lin ${ }^{4}$ \\ ${ }^{1}$ Department of Safety, Health and Environmental Engineering, Hungkuang University, Taichung 433, ROC Taiwan, \\ ${ }^{2}$ Department of Interior Design, Nan Jeon Institute of Technology, Tainan 737, ROC Taiwan, \\ ${ }^{3}$ Department of Marine Environmental Informatics, National Taiwan Ocean University, Keelung 202, ROC Taiwan, \\ ${ }^{4}$ Center for Weather Climate and Disaster Research, National Taiwan University, Taipei 106, ROC Taiwan,
}

\begin{abstract}
The purpose of this paper is to test the feasibility and affectivity of Bragg breakwaters on increasing wave energy by using wave conditions. The Bragg reflection phenomena will depend on the wavelength of surface waves and the spacing of the submerged breakwater. The spacing of the submerged breakwater is the most important parameter for designing a series of submerged breakwaters. In this paper, the Hybrid Mild-Slope Equation model (HMSE) was applied to calculate the phenomena of Bragg reflection and the feasibility and affectivity of ocean power. The data comprising wave records from three harbors in Taiwan during 1999 to 2004 were used to illustrate performance of this model. The effect and feasibility of Bragg breakwaters were also assessed in the practical cases. From the calculated results, the average of the ocean power comes to be 2.54 times more than the original condition in Keelung Harbor, 2.5 times in Su-Ao Harbor and 2.4 times in Hualien Harbor.
\end{abstract}

Keywords: Wave energy, Bragg reflection and Hybrid Mild-Slope Equation model.

\section{INTRODUCTION}

Taiwan is an island brimmed with the advantages of marine energy. According to the conversion method, marine energy can be classified into tidal energy, tidal/marine currents, wave energy and ocean thermal energy conversion (OTEC). There are also potential sources of the new energy including the natural gas hydrate found under the ocean. It is a white icy substance with lots of natural gas. Its organic carbon is about two times of the traditional fossil fuel. It is a very good source of green energy. The potential of Taiwan marine energy is as follows: Marine current: Marine current also known as the Black Current has the biggest potential for electricity generation. It is about $200-500 \mathrm{~m}$ thick and about $100-800 \mathrm{~km}$ wide with a velocity ranging from $0.5 \mathrm{~m} / \mathrm{sec}$ to $1 \mathrm{~m} / \mathrm{sec}$. It is theoretically feasible to use Black Current for electricity generation. But the deep water turbine generator is still under study.

Tidal: The biggest tide difference occurs in Kinman and Matsu off-shore islands. The tide difference is about $5 \mathrm{~m}$ at these places. The average tide difference is only about $3.5 \mathrm{~m}$ at western coast of Taiwan. This is below the economical tide difference of $6 \sim 8 \mathrm{~m}$. Because of the higher cost of generating electricity, it may be suitable to develop tidal energy in Kinman and Matsu off-shore islands.

*Address correspondence to this author at the Department of Interior Design, Nan Jeon Institute of Technology, Tainan 737, Taiwan, ROC;

Tel: +886-6-6523111 ext 6203; Fax: +886-6-6533821;

E-mail: prof.tllee@gmail.com
Wave energy: Because of seasonal wind, the wave energy is about $13 \mathrm{~kW} / \mathrm{m}$ at northern sea area and off-shore islands, $7 \mathrm{~kW} / \mathrm{m}$ at eastern and northwestern sea areas, and only $3 \mathrm{~kW} / \mathrm{m}$ at southwestern and southern sea areas. In Taiwan, around $100 \mathrm{MW}$ of stored wave energy could be developed.

Ocean thermal energy conversion: At southern Taiwan, the surface temperature of seawater in summer can be as high as $30^{\circ} \mathrm{C}$ and as low as $10^{\circ} \mathrm{C}$ under the sea with a difference of up to $20^{\circ} \mathrm{C}$. For the Black Current, the surface temperature of seawater is maintained at about $25^{\circ} \mathrm{C}$ and it is reduced to below $5^{\circ} \mathrm{C}$ under a depth of $800 \mathrm{~m}$. The temperature difference is also up to $20^{\circ} \mathrm{C}$. This temperature difference can be used for combined cooling and power utilization, the development of deep marine water and cultivation with very large economic efficacy.

Natural gas hydrate: A good deposit of natural gas hydrate was recently explored around the sea of Taiwan. According to a 2001 report of Central Geology Institute, its storage amount is more than 3.5 billion $\mathrm{m}^{3}$ at southwestern sea of Taiwan, which can produce about 600 billion $\mathrm{m}^{3}$ of natural gas.

Recently, selecting a shoreline protection method also depends on the physical processes that prevail at the project site. Under this system, the alternative structure does not increase the amount of sand available, it only redistributes available sand. Submerged breakwaters are generally shoreparallel and built near shore. The primary purpose is to retard 
offshore sand movement by introducing a structural barrier. The shore-parallel submerged breakwaters are likely to interrupt normal offshore sediment movement caused by storm waves. A distinction between nearshore breakwaters and submerged breakwaters can be made by noticing their effects on waves and sediment transport. Breakwaters reduce the intensity of waves; submerged breakwaters act as barriers to shore-normal sediment motion. By protecting shoreline method, the submerged breakwaters reduce onshore waves energy behind the submerged breakwaters and some wave energy is resisted in front of the submerged breakwaters.

Submerged breakwaters can be considered as nearshore breakwaters with crest elevations that are below the meantide level. Recently, the surface wave scattering by rippled seabed has been researched through both experiments and theories extensively. According to the results, as the surface wave number $k$ is equal to the half of bed wave number $K$, i.e. $2 k / K=1$, the Bragg reflection phenomena will be occurred. The effect of the Bragg reflection takes the energy of water waves away from the beach. The physics theories and experiments were used to examine the reflective mechanism of the Bragg resonance [1, 2]. In the experiments by Davies et al., the superimposition of two sinusoidal bottoms having different wave numbers $K_{1}$ and $K_{2}\left(K_{2}>K_{1}\right)$ and the relative amplitude of the bottom undulation $b / h$ ( $b$ is the amplitude of the bottom undulation, $h$ is the water depth), were referred to as sub-harmonic and higher-harmonic resonances $[3,4]$. Kirby and Anton [5] applied previous theories for Bragg reflection of surface waves by parallel bars to the case of artificial bars placed discretely on the seabed. Bailard et $a l$. [6] explored the feasibility of the Bragg reflection of artificial bars placed offshore on a natural beach. Their results concluded that the Bragg reflection of artificial bars may have merits as an appropriate shore protection method.

For designing a series of submerged breakwaters, waveheight and wave-period statistics are needed to determine the level of wave action to which various portions of a series submerged breakwaters will be subjected. Because of its Bragg reflection phenomena, wave-length and submerged breakwaters spacing will be limited. The spacing of the submerged breakwater is the most important parameter for designing a series of submerged breakwaters. According to theoretical results [1-4], the Bragg resonance occurs significantly at $2 k / K=1$, and the second-harmonic $2 k / K=2$ could also be found at the secondary resonance. The better efficiency of the reflection coefficients $R$ and in installing rectangular seabed spacing in between $3<S / B<4$ under the condition of the number of the submerged seabed is equal to 4 and the relative water-depth is equal to 0.5 [7]. As the width of the submerged breakwaters reaches 3.0, the reflection coefficient value $R_{\max }$ and the bandwidth of the Bragg reflection Bragg $_{B W}$ reach the stable values.

The bandwidth of the Bragg reflection $B{ } a g g_{B W}$ decreases with the decrease of the artificial bars number $N$ with different shapes [1, 8, 9]. Wen and Tsai [7] used numerous numerical experiments to investigate the characteristics of the Bragg reflection under 160,000 combinative condition of the rectangle seabed and wave incidence. In addition, they found that the peak reflection $R_{\max }$ increases with the rectangle seabed numbers $N$, and the values of $R_{\max }$ were found greater than 0.6 under the condition $S$ / $B$ between 2.6 and 4.0. Additionally, the values of $(2 S / L)_{\max }$ increase slightly as $N \geq 4$ under changing the condition of $D / h$ and $S / B$.

Based on the numerical experiment results [7], increasing the relative height of the submerged breakwaters will cause the peak of the reflection coefficients $R_{\max }$ shift toward lower frequency. The reason is that the total dispersion behavior by the interaction between the surface waves and undulating is stronger under the layouts of higher submerged breakwater height. Additionally, the bandwidth $B r a g g_{B W}$ increases on increasing $D / h$. These phenomena could also be found from the experimental results and the numerical results [7-10] for the artificial bars, sinusoidal bed or rectangle sea beds. Under the condition of $N$ being equal to 4, $D / h$ is found greater than 0.5 and $S / B$ greater than 2.33, the peak of the reflection coefficients $R_{\max }$ will be greater than 0.6 and the bandwidth Bragg $_{B W}$ will be 0.6.

The characteristics of the Bragg reflection for $R_{\max }$ and $B$ ragg $_{B W}$ are governed by the rectangular seabed layout and condition of incident waves including $S / B, N, D / h$ and $2 S / L$. The regression equation of the $R_{\max } \& B r a g g_{B W}$ is expressed as Equations. (1) and (2)

$$
\begin{aligned}
& R_{\max }=1-\exp \left[-0.413 N^{1.038}(S / B)^{0.455}(D / h)^{1.504}\right] \\
& \operatorname{Bragg}_{B W}=1.902 N^{-0.854}(S / B)^{-0.018}(D / h)^{0.083}
\end{aligned}
$$

Based on the numerical and experimental results and discussion mentioned above, the optimum designing of the waves' propagation over a series of submerged breakwaters is summarized in the following:

The peak of Bragg reflection $R_{\max }$ increases with increasing the submerged breakwater numbers $N$ and relative water depth $D / h$. As the relative submerged breakwaters spacing $S / B$ is set in the range of $3<S / B<4$, the Bragg reflection $R_{\max }$ and the bandwidth of the $B r a g g_{B W}$ reach the stable values. The ratio of the traverse breakwater distance, $S_{B}$ to the breakwater length, $G$ has the best efficiency while for traverse breakwater distance, $S_{B} / G \leq 0.25$ is better. In addition, the gap of the submerged breakwaters is suggested by the distances relative to the breakwater length, $G$ having well efficiency while $S_{G} / G \leq 0.75$.

The Bragg breakwaters could be used to protect coast and constructions in the sea. The Bragg breakwaters can be effective and feasible to be used to increase wave energy in the sea $[5,6,10,11]$. Therefore, the study of the impact of energy absorption by wave farms on the nearshore wave climate and specially the influence of the incident wave conditions and the number and position of the farms, on the near- 
shore wave characteristics has been performed and discussed in this paper. We will assess the maritime zone at the east coast of Taiwan, where it is foreseen the development of offshore wave energy prototypes and offshore distances 200 600m. In addition, the Hybrid Mild-Slope Equation model is used to calculate the phenomena of Bragg reflection and the feasibility and effectiveness of ocean power. On the whole, the data comprising wave records from Keelung, SuAo and Hualien Harbor in Taiwan during 1999 to 2004 were used to illustrate performance of this model.

\section{THE PILOT ZONE OFFSHORE WAVE CONDITIONS}

The wave data that this study has been based on was collected from Harbor and Marine Technology Center, Institute of Transportation, Ministry of Transportation and Communications. The data consists of time series of relevant wave parameters including wave height and wave period. Three different observation sites (Fig. (1)) were chosen in this study, Keelung Harbor, Su-Ao Harbor and Hualien Harbor during 1999 to 2004.

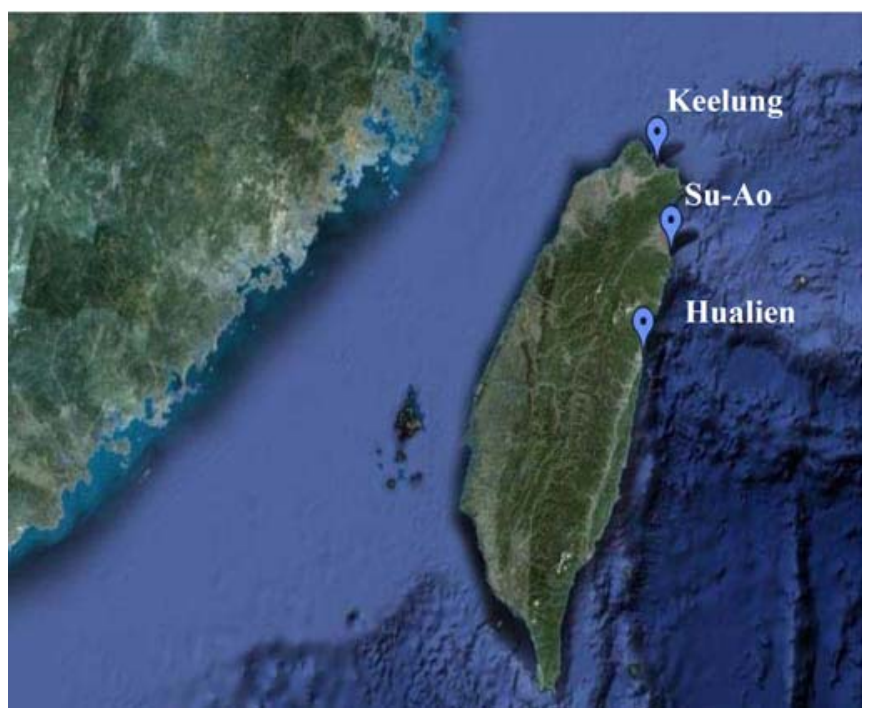

Fig. (1). Location of the Keelung Harbor, Su-Ao Harbor and Hualien Harbor in Taiwan.

Keelung Harbor is located in northern Taiwan and is bordered to the east by the Taiwan Strait. The latitude of Keelung is $25^{\circ} 09^{\prime} 11^{\prime \prime} \mathrm{N}$ and longitude is $121^{\circ} 44^{\prime} 57^{\prime \prime} \mathrm{E}$. The total area of Keelung Harbor is 572ha . The Su-Ao Harbor is located in northeast coast of Taiwan near the East China Sea. The total area of Su-Ao Harbor is 86ha. Its latitude is $24^{\circ} 35^{\prime} 40^{\prime \prime} \mathrm{N}$ and longitude is $121^{\circ} 52^{\prime} 32^{\prime \prime} \mathrm{E}$. Hualien Harbor is located in East Taiwan near the Pacific Ocean. The latitude of Hualien Harbor is $23^{\circ} 59^{\prime} 11^{\prime \prime} \mathrm{N}$ and longitude is $121^{\circ} 37^{\prime} 35$ ”'E. The total area of Hualien Harbor is 308ha .

Based on the wave data in Keelung Harbor, the value of significant wave height $H_{1 / 3}$ below $0.5 \mathrm{~m}$ is about $22.8 \%$, the value of average significant wave height is equal to $1.18 \mathrm{~m}$, which are $55.7 \%$ lower than $1 \mathrm{~m}$ and $27.9 \%$ between $1 \mathrm{~m}$ to $2 \mathrm{~m}$. According to the wave period analysis result, the value of significant wave period $T_{1 / 3}$ is $42.6 \%$ lower for that of 6 sec, $52.0 \%$ between 6 sec to 8sec. In Su-Ao Harbor, the value of significant wave height $H_{1 / 3}$ between $0.5 \mathrm{~m}$ and $1.0 \mathrm{~m}$ is about $31.2 \%$, the value of average significant wave height is equal to $1.25 \mathrm{~m}$, which are $40.9 \%$ lower than $1 \mathrm{~m}$, $47.1 \%$ between $1 \mathrm{~m}$ to $2 \mathrm{~m}$ and also $11.9 \%$ higher than $2.0 \mathrm{~m}$. According to the wave period analysis result, the value of significant wave period $T_{1 / 3}$ is $21.0 \%$ lower than $6 \mathrm{sec}$, $57.2 \%$ between $6 \mathrm{sec}$ to $8 \mathrm{sec}$. In Hualien Harbor, the value of significant wave height $H_{1 / 3}$ below $0.5 \mathrm{~m}$ is about $9.6 \%$, the value of average significant wave height is equal to $1.25 \mathrm{~m}$, which are $32.4 \%$ lower than $1 \mathrm{~m}, 54.2 \%$ between $1 \mathrm{~m}$ to $2 \mathrm{~m}$ and $13.4 \%$ higher than $2.0 \mathrm{~m}$. According to the wave period analysis result, the values of significant wave period $T_{1 / 3}$ are $18.1 \%$ lower than that for $6 \mathrm{sec}, 64.5 \%$ between 6 sec to $8 \mathrm{sec}$.

\section{METHODOLOGY}

Since standard meteorological data are available at more stations than the spectral wave data and they cover longer time periods, it is preferred to use them in calculating the wave power. However, using only a single wave height and a single average period to represent a spectrum of waves introduces errors in calculating the power. In order to have larger temporal and spatial coverage and space and to account for the error introduced by using the standard meteorological data the following method is used.

The wave power per unit crest with the energy equation for a monochromatic wave using the significant wave height and average period is given by

$$
P\left(H_{s}, T_{m}\right)=\frac{1}{8} \rho g H_{S}^{2} C_{g}
$$

where $P\left(H_{s}, T_{m}\right)$ is power for a monochromatic wave, $\rho$ is the density of water, $g$ is the gravitational acceleration, $H_{s}$ is the significant wave height and $C_{g}$ is the speed of the wave group or the speed of the energy, which is given by $C_{g}=1 / 2 \omega / k(1+2 k h / \sinh (2 k h))$ where $k$ is the wave number, and $\mathrm{h}$ is the water depth, and $\omega$ is the angular frequency given by $\omega=2 \pi f_{m}=2 \pi / T_{m}$ where $f_{m}$ is the average frequency, which corresponds to the average period of the spectrum. The power of irregular waves in a real sea state can be described by superposition of infinite number of regular waves with different heights and frequencies. Hence the frequency spectrum can be used to define power as

$$
P_{\text {spectral }}=\rho g \int_{f=0}^{\infty} S(f) C_{g}(f) d f
$$

Where $P_{\text {spectral }}$ power is calculated using the spectral energy density $S(f)$ and the wave frequency $f$. In practice, the wave records are finite in length and constructed with discrete sampling intervals. Similarly, the frequency spectrum is also constructed with finite number of frequency components, which is yielded as

$$
P_{\text {spectral }}=\rho g \sum_{i=1}^{N} S_{i}(C g)_{i} \Delta f
$$


Where $N$ is the number of frequency bands. $\Delta f$ is the width of the bands, $S_{i}$ is spectral energy density for each band, $\left(C_{g}\right)_{i}$ is the wave group speed for that frequency band. In order to compute the spectral power in the absence of spectral data, the assumption is made that the spectral power can be estimated from a single representative wave component through

$$
P_{\text {spectral }} \approx \alpha P\left(H_{s}, T_{m}\right)
$$

Where $\alpha$ is a coefficient whose value depends on the shape of the frequency spectrum that is used to define the sea state. In order to account for the realistic spectral shapes observed for the study area, a regression analysis of the relationship between (5) and (6) is done using the hourly data for the measured frequency spectra and the corresponding measured significant wave heights and average periods.

According to the studies, a coefficient of 0.49 is applied to the power calculated using the significant wave height and average period to obtain the power. The parameters of waves power $\left(H_{s}, T_{m}\right.$ and occurred probability $\chi$ ) are concerned in this model and expressed as

$P_{\text {corrected }}=0.49 \chi P\left(H_{s}, T_{m}\right)$

\section{THE WAVE MODEL}

In the approach presented here, the Hybrid Mild-Slope Equation model (HMSE) was chosen to calculate the phenomena of Bragg reflection and the feasibility and effectiveness of ocean power were distinguished in this paper. In order to simulate the practical conditions of wave height distribution, the small-amplitude regular waves propagating over rectangular breakwaters are considered. The fluid is considered to be incompressible and inviscid, the flow is irrotational, and the pressure is constant at the free surface. The nonlinear effects are also neglected in the model. For model formulation, a fixed rectangular coordinate $(x, y, z)$ with $z$ axis positive upward is used, $z$ equal to zero is located at the calm water level, and $(x, y)$ is the Cartesian coordinate with $x=$ onshore direction and $y=$ alongshore direction. The wave motion can be described by the potential $\Phi(x, y, z, t)$ which satisfies the Laplace equation and boundary conditions:

$$
\begin{aligned}
& \nabla_{h}^{2} \Phi+\Phi_{z z}=0, \text { at }-h^{\prime}(x, y) \leq z \leq 0 \\
& \Phi_{t t}+g \Phi_{z}=0, \text { at } z=0 \\
& \Phi_{z}=-\nabla_{h} h \cdot \nabla_{h} \Phi+\nabla_{h} \delta \cdot \nabla_{h} \Phi, \quad \text { at } z=-h^{\prime}(x, y)
\end{aligned}
$$

Where $h^{\prime}(x, y)$, consisting of a slowly varying component $h(x, y)$ and a rapidly varying component $\delta=\delta(x, y)$, is expressed as $h^{\prime}(x, y)=h(x, y)-\delta(x, y)$ and $t$ is the time; $\nabla_{h}=(\partial / \partial x, \partial / \partial y)$ is the horizontal gradient operator; $g$ is the gravitational acceleration; $C$ and $C_{g}$ are the wave veloc- ity and group velocity, respectively and $k$ is the wave number.

The Hybrid Model (HM) describes the interaction between surface waves and steep undulating bottoms consisting of slowly-varying and rapidly-varying components using the water-integrated method with added an empirical energy dissipation due to waves breaking $[9,10]$. The HM can be expressed as:

$$
\begin{aligned}
& \Phi_{t t}-\nabla_{h} \cdot\left(C C_{g} \nabla_{h} \Phi\right)+\left[\omega^{2}-k^{2} C C_{g}\left(1+i f_{d}\right)\right] \Phi \\
& +g\left(1-\lambda^{2}\right) \nabla_{h} \cdot\left(\delta \nabla_{h} \Phi\right) \\
& -g\left(2 F_{1} \cdot \delta \nabla_{h} \Phi+F_{1} \cdot \nabla_{h} \delta \tilde{\varphi}+F_{2} \Phi\right)=0
\end{aligned}
$$

Where

$$
\begin{aligned}
F_{1}= & \lambda\left(1-\lambda^{2}\right)\left(k \nabla_{h} h+h \nabla_{h} k\right) \\
F_{2}= & \alpha_{1}\left(\nabla_{h} h\right)^{2} k+\alpha_{2} \nabla_{h}^{2} h \\
& +\alpha_{3} \nabla_{h} k \cdot \nabla_{h} h / k+\alpha_{4} \nabla_{h}^{2} k / k^{2} \\
& +\alpha_{5}\left(\nabla_{h} k\right)^{2} / k^{3}
\end{aligned}
$$

where $\lambda=\tanh k h$ and the parameters $\alpha_{i}(i=1,5)$ are

$$
\begin{aligned}
\alpha_{1}= & -\lambda\left(1-\lambda^{2}\right)(1-\lambda q)-2\left(1-\lambda^{2}\right) \lambda^{2} k \delta \\
\alpha_{2}= & -\lambda q\left(1-\lambda^{2}\right) / 2+\left(1-\lambda^{2}\right) \lambda k \delta \\
\alpha_{3}= & q\left(1-\lambda^{2}\right)\left(2 q \lambda^{2}-5 \lambda / 2-q / 2\right) \\
& -2\left(1-\lambda^{2}\right)\left(2 \lambda^{2} q-\lambda-q\right) k \delta \\
\alpha_{4}= & q\left(1-\lambda^{2}\right)(1-2 \lambda q) / 4-\lambda / 4 \\
& +\left(1-\lambda^{2}\right) \lambda q k \delta \\
\alpha_{5}= & q\left(1-\lambda^{2}\right)\left(4 \lambda^{2} q^{2}-4 q^{2} / 3-2 \lambda q-1\right) / 4 \\
& +\lambda / 4+\left(1-\lambda^{2}\right) q^{2}\left(1-2 \lambda^{2}\right) k \delta
\end{aligned}
$$

The notation $q=k h$ is used for convenience. $i=\sqrt{-1}$ is a unit complex number, $f_{d}$ is the energy dissipation coefficient and is written as

$$
f_{d}=\frac{5}{2} \tan \beta \sqrt{\frac{1}{k_{0} h}} \sqrt{\frac{\gamma-\gamma_{r}}{\gamma_{s}-\gamma_{r}}}
$$

where

$$
\begin{aligned}
& \gamma=a / h \\
& \gamma_{r}=0.135 \\
& \gamma_{s}=0.4 \times(0.57+5.3 \tan \beta)
\end{aligned}
$$

$\tan \beta$ is the average bottom slope around the breaking point, $k_{0}$ is the deep water wave number, $\gamma$ is the ratio of the amplitude of surface waves to the water depth for judging the wave breaking, a is the amplitude of water surface, $\gamma_{r}$ denotes the critical value of a recovery wave on a constant water depth, and $\gamma_{s}$ represents the ratio of the wave 
height to water depth on uniform slopes. A breaking index $\gamma_{b}$ is used as a breaking criterion defined by

$$
\begin{aligned}
\gamma_{b}= & 0.53-0.3 \exp \left(-3 \sqrt{h / L_{0}}\right) \\
& +5 \tan \beta^{3 / 2} \exp \left[-45\left(\sqrt{h / L_{0}}-0.1\right)^{2}\right]
\end{aligned}
$$

where $L_{0}$ is the deep water wavelength. In each iterative time step, the values of $\gamma$ and $\gamma_{b}$ are calculated and compared. The value of $f_{d}$ equals zero as $\gamma<\gamma_{b}$; otherwise, $f_{d}$ is estimated from Eq. (19). For practical coastal profiles, the rapidly-varying terms, bottom slope $\nabla_{h} h$, bottom curvature $\nabla_{h}^{2} h$, and the rapidly varying component $\delta=\delta(x, y)$ played an important role in the practical topography. Hybrid Model can describe the slowly-varying components to reduce the error in the dispersion relation. The wave number $k$ can be obtained from the linear dispersion equation with known angular frequency $\omega$ and water depth $h$. The dispersion relationship is expressed as $\omega^{2}=g k \tanh k h$.

In order to improve the computational speed, a slow coordinate was introduced for the time variable, $\bar{t}=\varepsilon t$, and the transformation of scaling factor $\tilde{\phi}(x, y, t, \bar{t})=\phi(x, y, \bar{t}) e^{-i \omega t} / \sqrt{\left[C C_{g}-g\left(1-\lambda^{2}\right) \delta\right]} \quad(\varepsilon=\quad \mathrm{a}$ perturbation parameter of order $\left.O\left(\nabla_{h} h / k h\right)\right)$ to obtain an Evolution Equation for the Mild-Slope Equation (EEMSE) from Eq. (10), the procedure outlined by Hsu et al. (2003):

$$
\begin{aligned}
& {\left[\frac{-2 \omega i}{C C_{g}-g\left(1-\lambda^{2}\right) \delta}\right]\left(\frac{\partial \phi}{\partial t}\right)=\nabla_{h}^{2} \phi+k_{c}^{2} \phi} \\
& +\frac{g}{\sqrt{C C_{g}-g\left(1-\lambda^{2}\right) \delta}}\left[2 \vec{F}_{1} \cdot \delta \nabla_{h} \frac{\phi}{\sqrt{C C_{g}-g\left(1-\lambda^{2}\right) \delta}}\right] \\
& +\frac{\delta}{\sqrt{C C_{g}-g\left(1-\lambda^{2}\right) \delta}} \nabla_{h}\left[g\left(1-\lambda^{2}\right)\right] \cdot \nabla_{h}\left[\frac{\phi}{\sqrt{C C_{g}-g\left(1-\lambda^{2}\right) \delta}}\right]
\end{aligned}
$$

where

$$
\begin{aligned}
k_{c}^{2}= & {\left[\frac{g \vec{F}_{1} \cdot \nabla_{h} \delta+g F_{2}+k^{2} C C_{g}\left(1+i f_{d}\right)}{C C_{g}-g\left(1-\lambda^{2}\right) \delta}\right] } \\
& -\frac{\nabla_{h}^{2} \sqrt{C C_{g}-g\left(1-\lambda^{2}\right) \delta}}{\sqrt{C C_{g}-g\left(1-\lambda^{2}\right) \delta}}
\end{aligned}
$$

is the pseudo wave number.

In order to simulate the practical situation, two types of boundary conditions are used in the computational domain. One is a partial reflection boundary condition and the other is a given boundary condition. These boundary conditions reduce the reflected waves from the boarder to the computational domain. The boundary conditions are given as follows.

$$
\frac{\partial \phi}{\partial x}= \pm(-1)^{m} i \alpha k \cos \theta \phi+2 i k \cos \theta \phi_{i}, \text { on } \pm x
$$

$\frac{\partial \phi}{\partial y}= \pm(-1)^{m} i \alpha k \sin \theta \phi+2 i k \sin \theta \phi_{i}, \quad$ on $\pm y$

Where $\alpha=(1-R) /(1+R)$ is an absorption coefficient, $R$ is the reflection coefficient, and the subscript " $i$ ", denotes a quantity of the incident wave. For the partial reflection boundary, $\phi_{i}=0, m=0$, and $0<\alpha \leq 1$.

For the given boundary condition, $m=1, \alpha=1$ and $\phi_{i}=(a g / \omega) e^{i S_{0}}, \quad S_{0}=k x \cos \theta_{i}+k y \sin \theta_{i}-\omega t$, and $\theta_{i}$ is the incident wave angle.

\section{FEASIBILITY AND EFFECTIVENESS OF BRAGG REFLECTION}

According to the offshore wave conditions and wave power calculation method for the conditions without and with submerged breakwaters, east Taiwan ocean power can be calculated by using the standard meteorological data.

The plane displacement of the above breakwater crosssectional design is implemented on-site as $N=4, B=20 \mathrm{~m}, S_{B}$ $=40 \mathrm{~m}$ and $h=-8 \mathrm{~m}$ for the first breakwater nearest to seashore. The distance of the laying position depends on the water depth and the distance from offshore is calculated about $600 \mathrm{~m}$.

In Keelung Harbor, as original waves condition, as $T_{z}$ is equal to $6.5 \mathrm{sec}$, ocean power has higher value and it reaches to $1.1 \mathrm{~kW} / \mathrm{m}$, as shown in Fig. (2).

By setting a series submerged breakwaters, $N=4$, $D / h=0.8, S / B=2.0$, the ocean power will be increased and wave power will reach to $2.8 \mathrm{~kW} / \mathrm{m}$, as shown in Fig. (3). Comparison of the ocean power with effect of Bragg reflection and original condition, will help increase the ocean power by setting a series of submerged breakwaters within the Bragg $_{B W}$, as shown in Fig. (4).

The same was performed for Su-Ao Harbor, as original waves condition, as $T_{z}$ is equal to $7.5 \mathrm{sec}$, ocean power has higher value and it reaches to $0.6 \mathrm{~kW} / \mathrm{m}$, as shown in Fig. (5).

By setting a series submerged breakwaters, $N=4$, $D / h=0.8, S / B=2.0$, the ocean power will be increased and wave power will reach to $1.5 \mathrm{~kW} / \mathrm{m}$, as shown in Fig. (6). Comparison of the ocean power with effect by Bragg reflection and original condition, will help maximize the ocean power by setting a series of submerged breakwaters within the $\mathrm{Bragg}_{B W}$, as shown in Fig. (7).

In Hualien Harbor, as original waves condition, as $T_{z}$ is equal to $6.5 \mathrm{sec}$, ocean power has higher value and it reaches to $1.0 \mathrm{~kW} / \mathrm{m}$, as shown in Fig. (8).

By setting a series of submerged breakwaters, $N=4$, $D / h=0.8, S / B=2.0$, the ocean power will be increased and wave power will reach to $2.4 \mathrm{~kW} / \mathrm{m}$, as shown in Fig. (9). Comparison of the ocean power being affected by Bragg reflection and original condition, will help increase the ocean 
power by setting a series of submerged breakwaters within the Bragg $_{B W}$, as shown in Fig. (10).

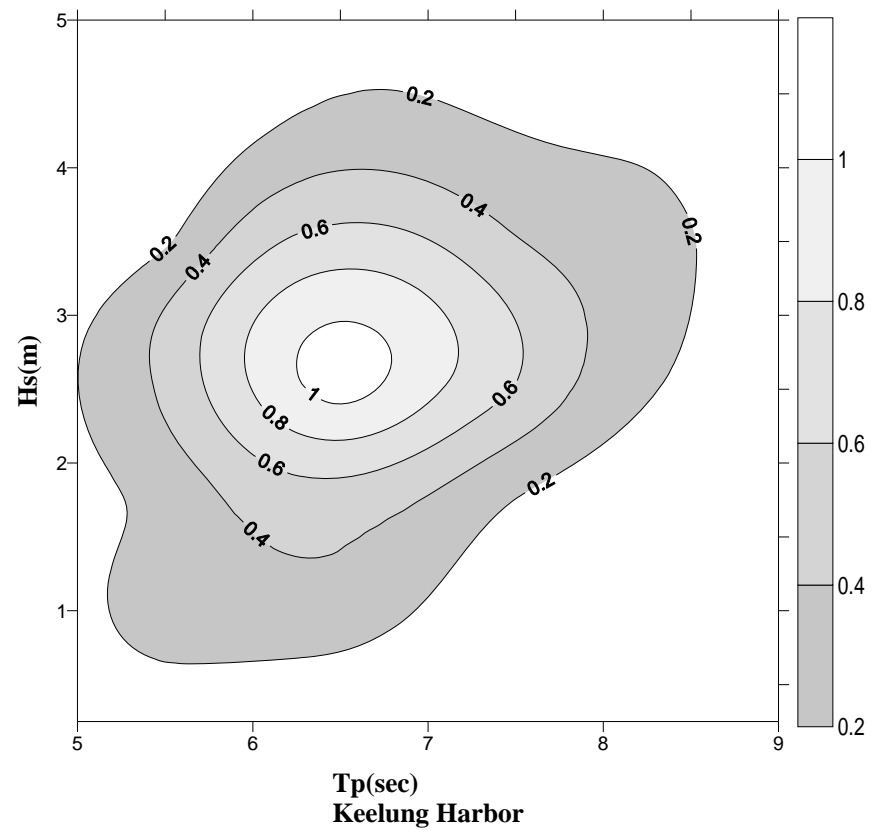

Fig. (2). Distribution of ocean power in Keelung Harbor without submerged breakwaters.

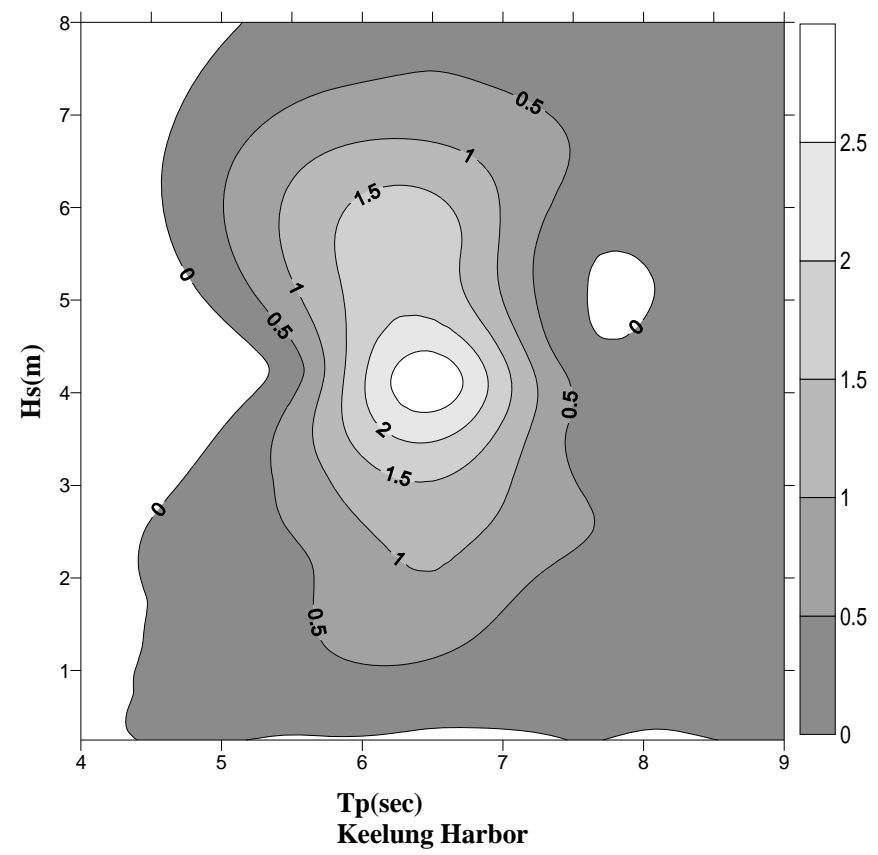

Fig. (3). Distribution of ocean power in Keelung Harbor with submerged breakwaters. $(\mathrm{N}=4, \mathrm{D} / \mathrm{h}=2$ and $\mathrm{S} / \mathrm{B}=2.0)$.

\section{CONCLUSIONS}

This paper is to analyze and distinguish the feasibility and effectiveness of using Bragg breakwaters for Taiwan ocean energy. The Bragg reflection phenomena are likely to depend on the wavelength of surface waves and the spacing of the submerged breakwater. The data consists of wave records which provide the following wave parameters: $H_{s}$ (significant wave height) and $T_{2}$ (mean wave period). The data refers to the period from 1999 to 2004. According to the offshore wave conditions and wave power calculation method for the conditions with and without submerged breakwaters, it relates that ocean power can be increased by creating the Bragg reflection effects in the offshore zone. For that, the average of the ocean power will be 2.54 times more than the original condition in Keelung Harbor, 2.5 times more in Su-Ao and 2.4 times more in Hualien. Additionally, the application in this research is limited to regular waves, rectangular breakwater body and impermeable material. Future applications are recommended to consider different breakwater shapes, permeable material, combinations of various breakwater lengths and irregular incoming waves such that the results are more applicable to the real situation.

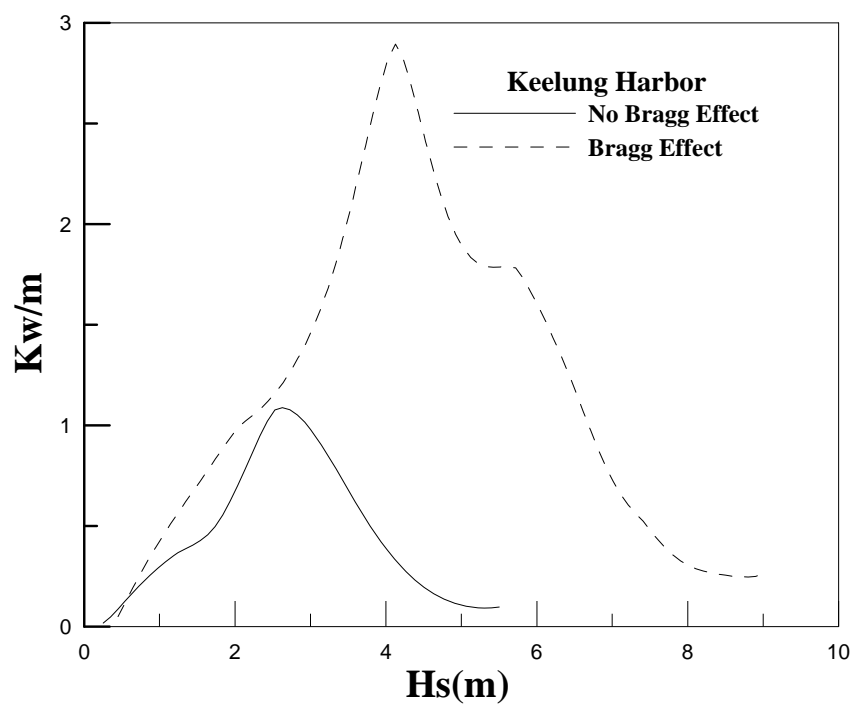

Fig. (4). Comparison of ocean power with Bragg reflection effect and without Bragg reflection effect in Keelung Harbor $\left(T_{z}=6.5 \mathrm{sec}\right)$.

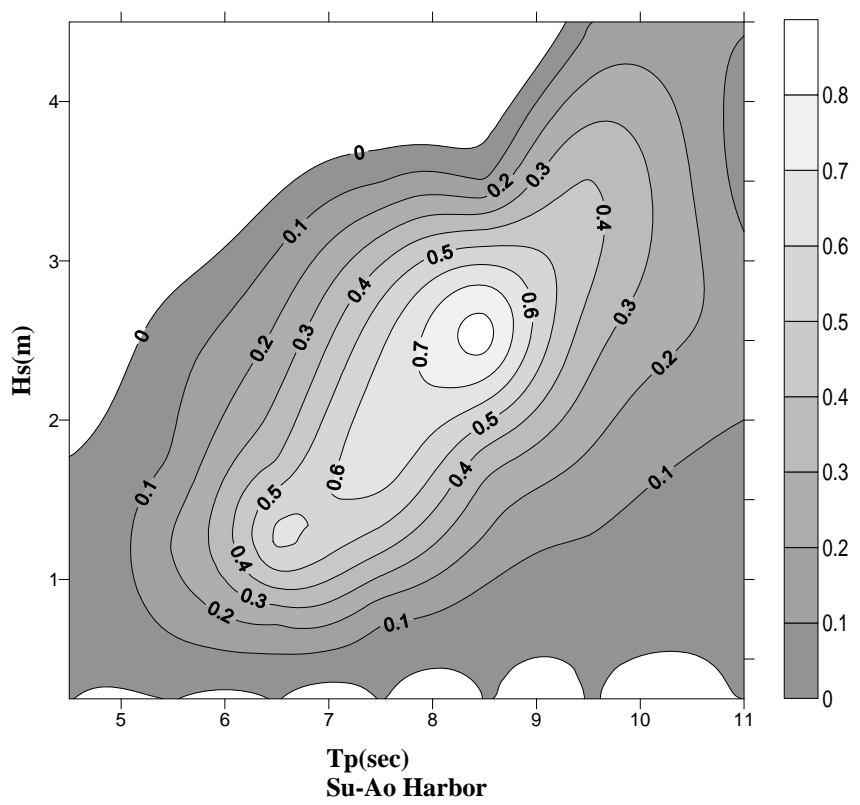

Fig. (5). Distribution of ocean power in Su-Ao Harbor without Bragg reflection effect. 


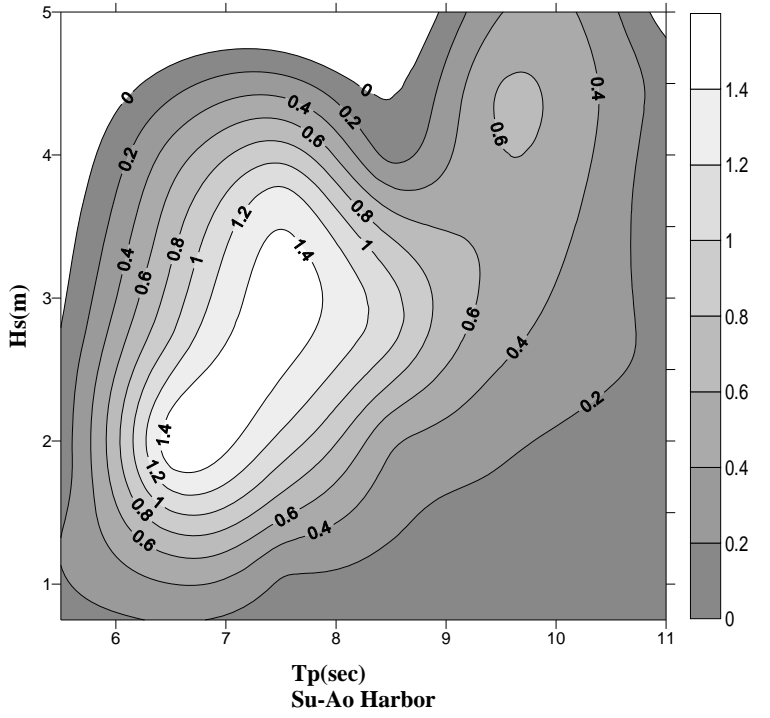

Fig (6). Distribution of ocean power in Su-Ao Harbor with Bragg reflection effect. $(\mathrm{N}=4, \mathrm{D} / \mathrm{h}=2$ and $\mathrm{S} / \mathrm{B}=2.0)$.

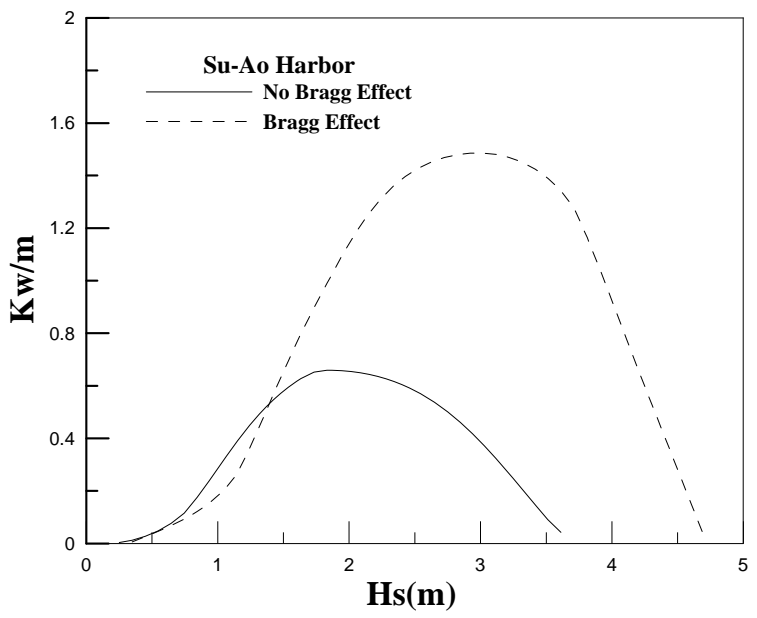

Fig. (7). Comparison of ocean power with Bragg reflection effect and without Bragg reflection effect in Su-Ao Harbor $\left(T_{z}=7.5 \mathrm{sec}\right)$.

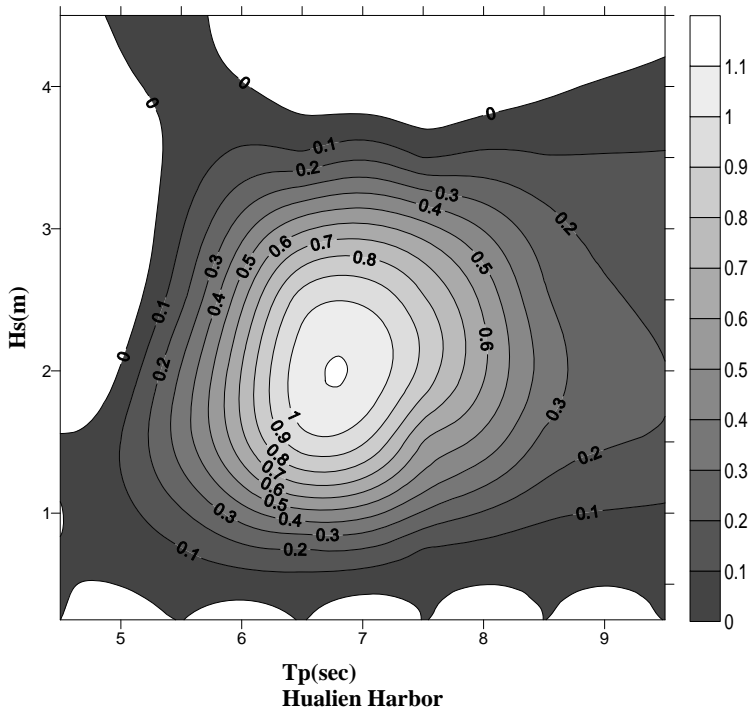

Fig. (8). Distribution of ocean power in Hualien Harbor without Bragg reflection effect.

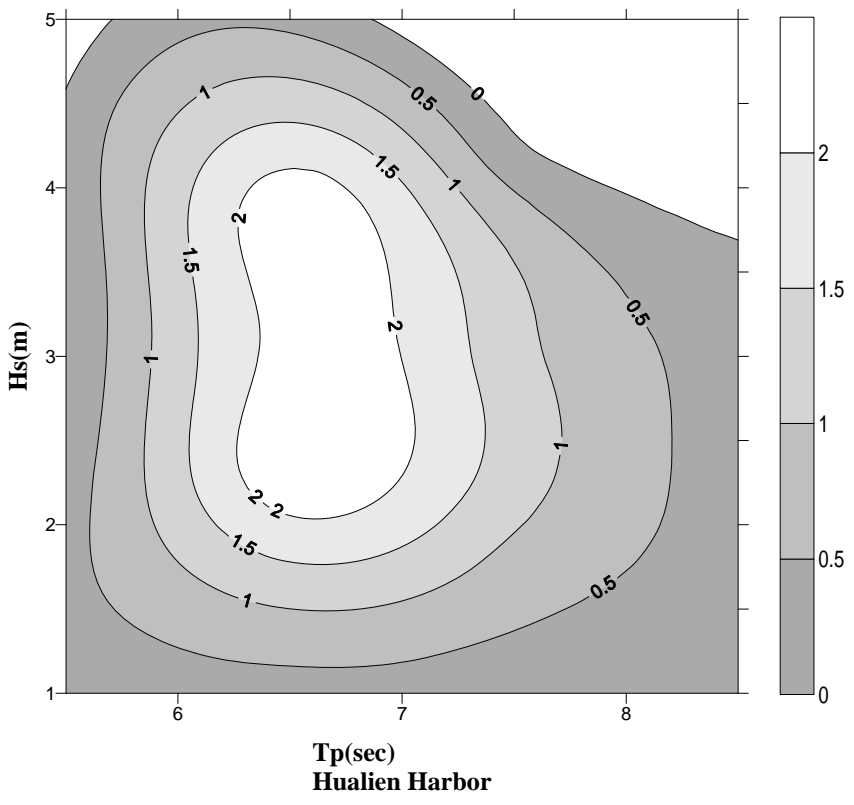

Fig. (9). Distribution of ocean power in Hualien Harbor with Bragg reflection effect. $(\mathrm{N}=4, \mathrm{D} / \mathrm{h}=2$ and $\mathrm{S} / \mathrm{B}=2.0)$.

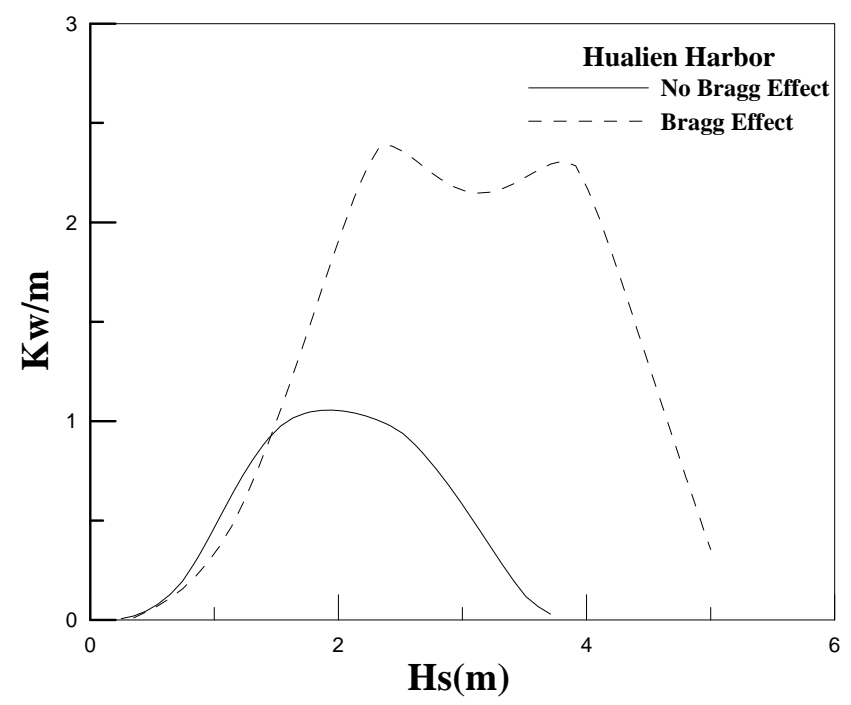

Fig. (10). Comparison of ocean power with Bragg reflection effect and without Bragg reflection effect in Hualien Harbor $\left(T_{z}=6.5 \mathrm{sec}\right)$.

\section{REFERENCES}

[1] G. Davies, and A. D. Heathershaw, "Surface wave propagation over sinusoidally varying topography," Journal of Fluid Mechanics, vol. 144, pp. 419-443, 1984.

[2] C. Mei, "Resonance Reflection of Surface Waves by a Periodic Sandbars," Journal of Fluid Mechanics, vol.152, pp. 315-335, 1985.

[3] G. Davies, E. Guazzelli, and M. Belzons, "The Propagation over Sinusoidally Varying Topography,” Physical. Fluids., vol. 144 (A1-8), pp. 1331-134, 1989.

[4] T. J. O'Hare, and A. G. Davies, "A Comparison of Two Models for Surface-wave Propagation over Rapidly Topography,” Applied. Ocean. Research., vol. 15, pp. 1-11, 1993.

[5] J. T. Kirby, and J. P. KAnton, "Bragg reflection of waves by artificial bars," In: Proceedings 22th International Conference on Coastal Eng., ASCE, pp. 757-768, 1990.

[6] J. A. Bailard, J. W. DeVries, and J. T. Kirby, "Considerations in using Bragg reflection for storm erosion protection. Journal of 
Waterway, Port, Coastal and Ocean Engineering., vol. 118, no. 1, pp. 63-74, 1992.

[7] C. Wen, and L. H. Tsai, "Numerical simulation of Bragg reflection based on linear waves propagation over a series of rectangular seabed," China Ocean Engineering., pp. 71-86. 2008.

[8] E. Guazzelli, V. Rey, and M. Belzons, "Higher-order Bragg reflection of gravity surface waves by periodic beds," Journal of Fluid Mechanics, vol. 245, pp. 301-317, 1992.
[9] T. W. Hsu, L. H. Tsai, and Y. T. Huang, "Bragg Scattering of Water Waves by Multiply Composite Artificial Bars," Coastal Engineering Journal., vol. 45, no. 2, pp. 235-253, 2003.

[10] L. Zhang, M. H. Kim, J. Zhang, and B. L. Edge, "Hybrid Model for Bragg Scattering of Water Waves by Steep Multiply-sinusoidal Bars,” Journal of Coastal Research, vol. 15, no. 2, pp. 486-495, 1999.

[11] C. Mei, T. Hara, and M. Naciri, "Note on Bragg Scattering of Water Waves by Parallel Bars on the Seabed," Journal of Fluid Mechanics, vol. 186, pp. 147-162, 1988.

(C) Wen et al.; Licensee Bentham Open.

This is an open access article licensed under the terms of the Creative Commons Attribution Non-Commercial License (http://creativecommons.org/licenses/ by-nc/3.0/) which permits unrestricted, non-commercial use, distribution and reproduction in any medium, provided the work is properly cited. 